\title{
A two-step, one pot preparation of amines via acyl succinimides. Synthesis of the calcimimetic agents cinacalcet, NPS R-467, and NPS R-568
}

\author{
Cassie A. Gooodman, Elise Marie Janci, Olivia Onwodi, Chad C. Simpson, \\ Christopher G. Hamaker, and Shawn R. Hitchcock*
}

Department of Chemistry, Illinois State University, Normal, IL 61790-4160

*Corresponding author: Tel.: 309-438-7854. Fax: 3009-438-5538. E-mail: Hitchcock@illinoisstate.edu
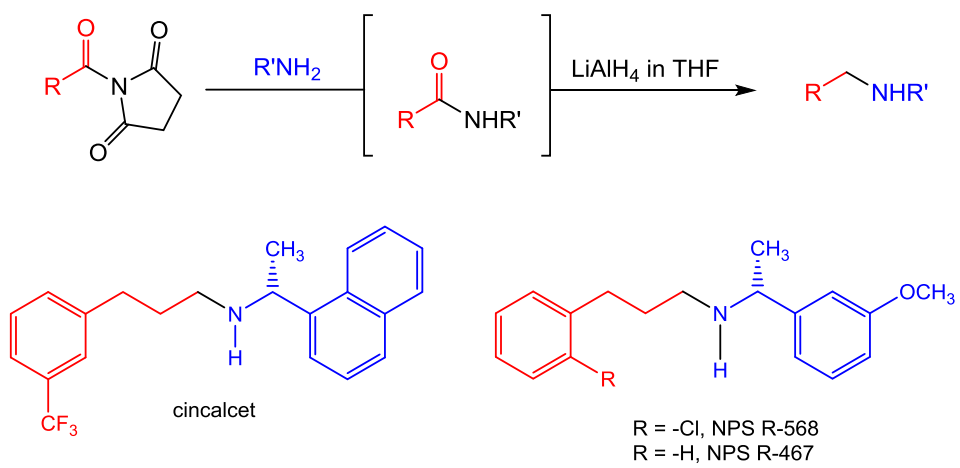

Abstract-A method has been developed for the preparation of amines through a process of coupling acyl succinimides derived from commercially available carboxylic acids with amines to afford the corresponding amides. These amides are then reduced in situ with either diisobutylaluminum hydride or lithium aluminum hydride. The reaction tandem of the coupling reaction followed by the reduction affords the amine in fair to good yield after purification by flash chromatography. This one-pot, two reaction tandem process has been successfully applied to the synthesis of the calcimimetic agents cinacalcet, NPS R-467, and NPS R-568.

Key words: succinimide, cinacalcet, NPS R-467, NPS R-568, acyl succinimide, reductive amination

Acyl succinimides are activated amides that can be readily prepared from by the reaction of acyl chlorides with succinimide or by the reaction of carboxylic acids with carbodiimides and succinimide. ${ }^{1}$ These compounds have received little attention, but have the potential for use in a variety of applications. Reductive amination is one of the most common methods employed for the synthesis of amines. There was an interest in employing the acyl succinimides in a two-step, one pot process for the synthesis of amines by a acyl coupling/reduction tandem (Figure 1). The process would be a carboxyl equivalent of reductive amination. ${ }^{2}$ The utility in this methodology would involve the conversion of the carboxylic acid into an acyl succinimide for the coupling/reduction process. This would potentially require less work than converting the carboxylic acid to the aldehyde for the purpose of a reductive amination. This methodology would not be viable with other carboxyl derivatives. The formation of an amide from an acyl chloride ${ }^{3}$ and an amine would generate the protonated scavenger base (e.g., $\mathrm{Et}_{3} \mathrm{NHCl}$ ) that would react violently with any reducing agents in the second stage of the reaction. Another example of an incompatible process would involve the use of a carbodiimide (e.g., DCC, DMAP) to couple a carboxylic acid and an amine. ${ }^{4}$ The resultant amide would be formed along with N,N'-dicyclohexylurea. The urea side product would react with any reducing agent and would complicate the reaction mixture. Activated esters such as $p$ nitrophenyl esters, ${ }^{5} \mathrm{~N}$-hydroxysuccinimide esters, ${ }^{6}$ or acyl imidazoles ${ }^{7}$ would also involve problematic features, primarily the byproducts of the acyl coupling reacting with the reducing agent. In contrast, acyl succinimides can be easily prepared from carboxylic acids and readily undergo coupling with amines to afford the corresponding amide with succinimide as the only side product. These combined factors would be optimal for a one-pot 
process of coupling and reduction. The process of conducting the coupling/reduction tandem reactions in a single vessel is described as well as the synthesis of the calcimimetic agents cinacalcet (sensipar ${ }^{\circledR}$ ), NPS R-467 and NPS R-568.

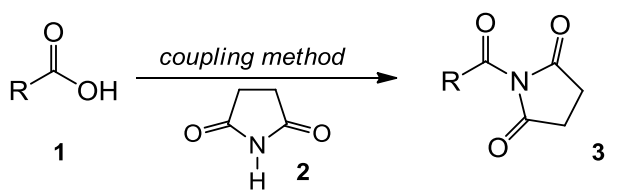

Two step, one pot tandem

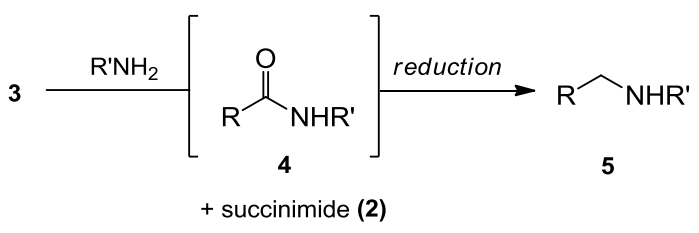

Figure 1. Reductive amination with acyl succinimides.

This work began with the preparation of 3phenylpropanoyl succinimide (7) as a model compound for the acyl coupling/reduction tandem. This succinimide was prepared in $70 \%$ yield by the reaction of 3-phenylpropanoic acid with EDC, DMAP, and succinimide (Scheme 1). There was also an interest in forming the acyl succinimide of 3,4dimethoxyphenylacetic acid as this compound would serve as a potential intermediate in the synthesis of the anti-arrythmic agent denopamine. ${ }^{8}$ Under the conditions that were employed, this carboxylic acid formed diketone 9. This was unexpected and may have occurred through a process of formation of the activated acyl DMAP derivative followed by a Claisen type condensation and concomitant decarboxylation. The formation of the corresponding diketone was not observed in the case of the formation of the 3-phenylpropanoyl succinimide suggesting that this was limited to this substrate.

With acyl succinimide 7 in hand, the tandem process of the coupling reaction and the reduction of the amide in situ was explored (Table 1). To this end, acyl succinimide 7 was reacted with amines 1015 for 18 hours at the end of which time Dibal-H (8 equivalents) (entries 1-3) or lithium aluminum hydride (entries 4-6) was added dropwise. The temperature was raised to reflux for 18 hours. The overall process was successful and yielded the desired amines 16-21 in a two-step, one-pot process in yields ranging between $42-72 \%$.
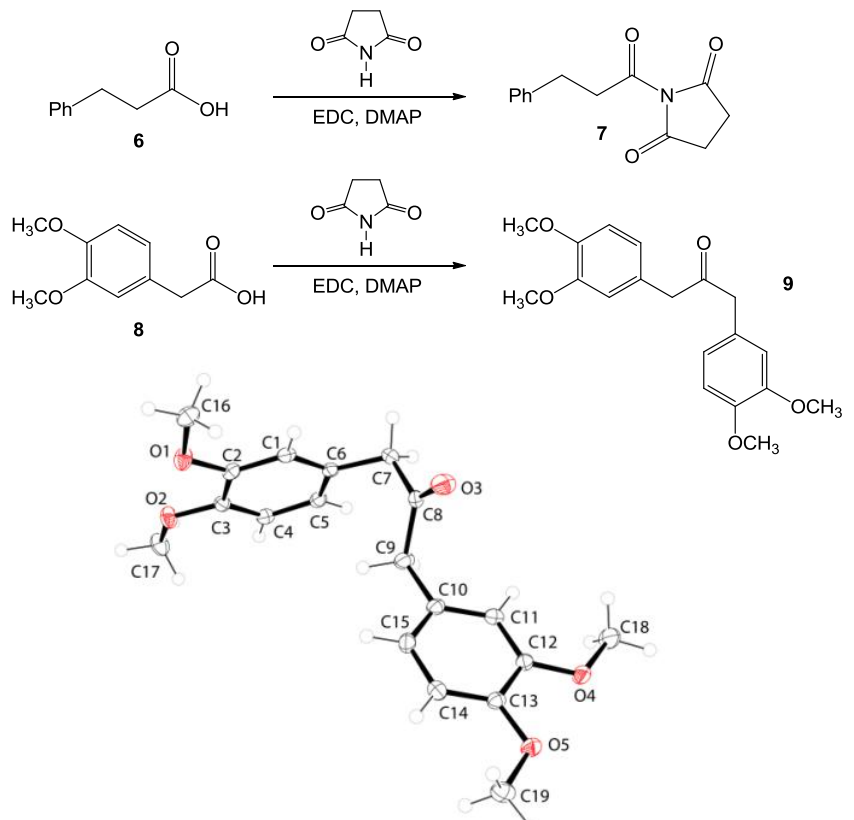

Scheme 1. Unexpected symmetrical ketone formation and X-ray crystal structure of $\mathbf{9}$.

Cincalcet (24) is a calcimimetic agent used to treat secondary hyperparathyroidism and has been previously synthesized by a variety of methods including a reductive amination pathway involving the Forster reaction. The principle method that has been used to prepare cinacalcet has involved the coupling of the chiral amine $(R)-\mathbf{1 2}$ with the phenylpropanoic acid derivative $\mathbf{2 2}$ to form an amide that is isolated and then subsequently reduced (Scheme 2). ${ }^{9-13}$

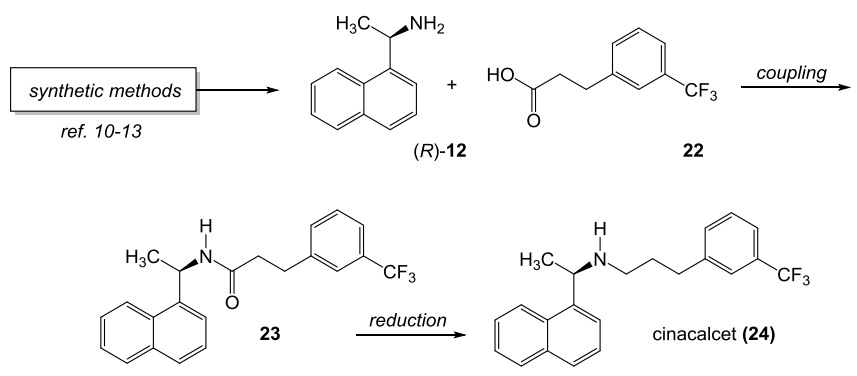

Scheme 2. Syntheses of cinacalcet (21).

Ortiz-Marciales and co-workers developed a method for the asymmetric synthesis of non-racemic primary amines based on an amido-spiroborate catalyzed reduction of $O$-benzyloximes. ${ }^{11}$ This methodology was used to synthesize the necessary amine $(R)-12$. With the amine in hand, they were able to prepare cinacalcet using an efficient coupling pathway followed by a reduction. Other methods directed at the preparation of cinacalcet require the same number of steps or more. ${ }^{14,15}$ 
Table 1. Two step, one pot synthesis of amines from acyl succinimides.

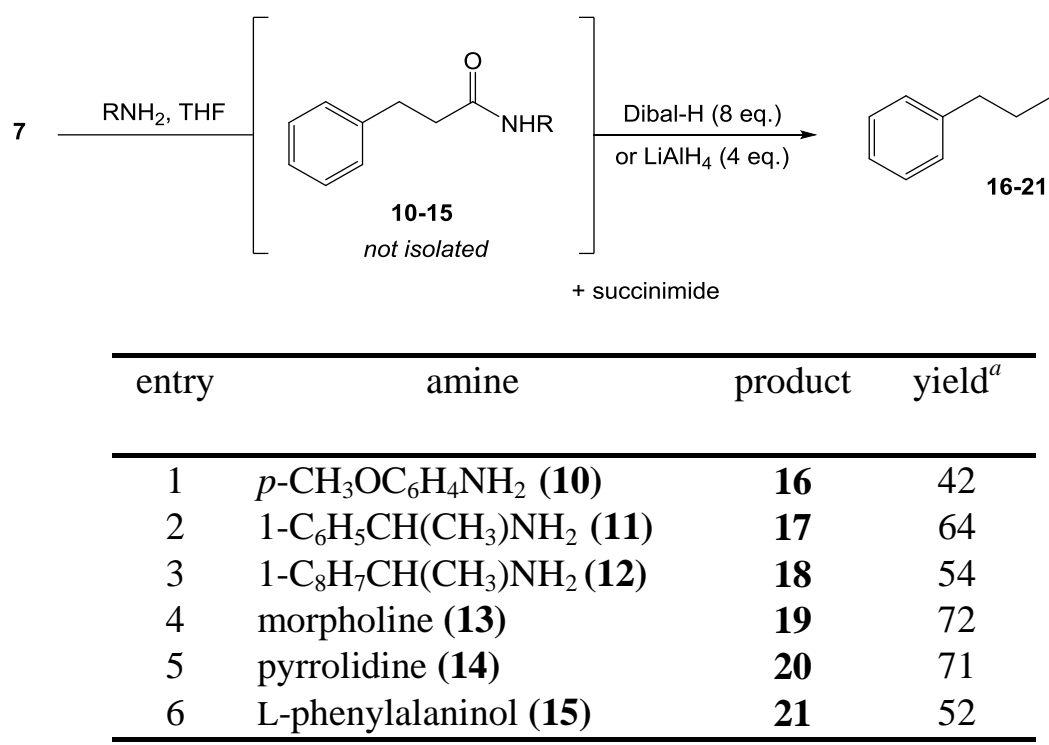

${ }^{a}$ Isolated chemical yield after flash chromatography.

The advantage to the acyl succinimide method is that the amine component of the coupling reaction is carried through two chemical transformations in a single vessel. The chiral amine is usually the more expensive component of the reaction. Ultimately, it would be beneficial for the amine to be used in as few synthetic steps as possible. In this context, the synthesis of cinacalcet using the tandem one-pot acyl succinimide coupling/reduction pathway was explored (Scheme 3). The acyl succinimide was first prepared from commercially available trans-(3trifluoromethyl)-3-phenylpropenoic acid (22). This material was treated with $\mathrm{H}_{2}$ over $\mathrm{Pd} / \mathrm{C}$ to afford the corresponding 3-(trifluoromethyl)-3-phenylpropanoic acid (23) in $85 \%$ yield. The carboxylic acid was then converted to the 3-phenylpropanoyl succinimide $\mathbf{2 4}$ by reaction with EDC, DMAP and succinimide. This process yielded $\mathbf{2 4}$ as a crystalline solid in $44 \%$ isolated yield after recrystallization. The succinimide was then treated with $(R)$-1-naphthylethylamine (12) and stirred for $18 \mathrm{~h}$. The reaction mixture was then treated with Dibal-H and stirred overnight at reflux. The target cinacalcet (25) was obtained in 54\% yield after flash chromatography. The acyl succinimideDibal-H reduction pathway was successful, but the yield of the two-step, one pot synthesis was optimized to $54 \%$. In addition to this, the reaction was capricious in terms of the isolated chemical yield. At this stage, the use of an alternate reducing agent was considered in order to circumvent the difficulties associated with the use of Dibal-H. The application of borane $\left(\mathrm{BH}_{3}-\mathrm{THF}, \mathrm{BH}_{3}\right.$-DMS, $\mathrm{NaBH}_{4}$,
$\mathrm{I}_{2}$ ) as a reducing agent failed to generate the product. In contrast, lithium aluminum hydride was considered to be ideal for the removal of the succinimide by its reduction to its corresponding pyrrolidine or the 4-aminobutanol derivative. ${ }^{15}$ There was a concern that the trifluoromethyl group might be susceptible to over reduction. However, Ono and coworkers had demonstrated that this moiety is stable to such reduction conditions. ${ }^{16}$ The use of lithium aluminum hydride as a powder gave inconsistent results after numerous trials. In contrast, a solution of lithium aluminum hydride ( $2 \mathrm{M}$ in $\mathrm{THF}$ ) gave results that were much improved as multiple runs yielded consistent results (Scheme 3).
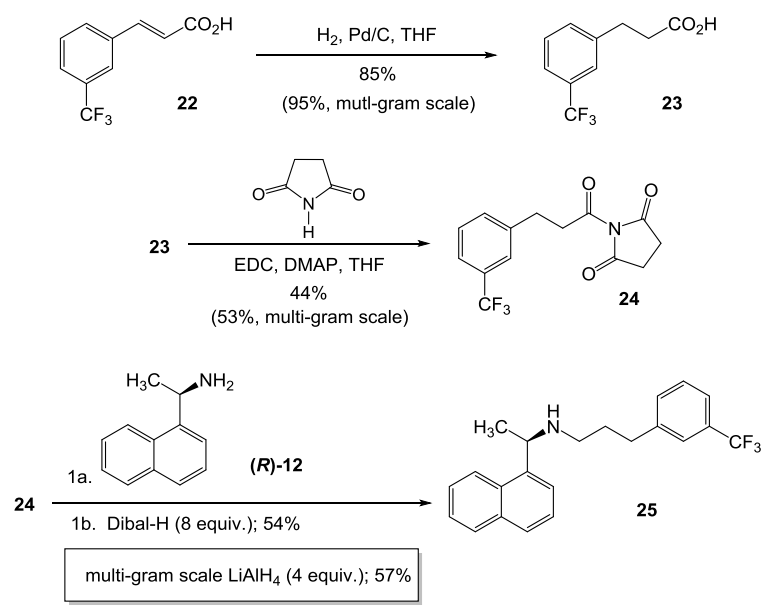

Scheme 3. Synthesis of cinacalcet via an acyl succinimide approach. 
We were gratified to learn that the two-step, one pot reaction worked well and yielded cinacalcet in a $57 \%$ yield. The process proved to be consistent and reproducible and only required a single reaction vessel to achieve the synthesis of the product. It was at this point that we considered demonstrating the utility of this process by applying it to other calcimimetic agents.

NPS R-467 (27) and NPS R-568 (31) are calcimimetic agents that have been described in the literature ${ }^{18}$ and have been prepared by a variety of methods. ${ }^{19-28}$ The most common method of preparation of these amines was the coupling of a carboxylic acid with the necessary chiral amine fragment followed by a second reaction (reduction). The current method of the two-step, one pot method was applied to the synthesis of NPS R-467 and NPS R-568. NPS R-467 was prepared in this manner by reacting the acyl succinimide (7) with $(R)$-3-methoxy phenyl ethylamine $[(\boldsymbol{R})-26]$ followed by reduction with lithium aluminum hydride yielded the target NPS R-467 in $71 \%$ yield after purification (Scheme $4)$.

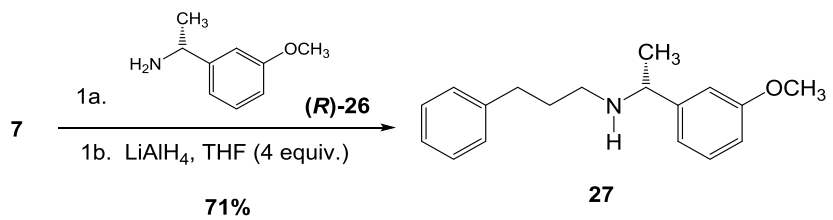

Scheme 4. Two-step, one pot synthesis of NPS R467.

With the success and improved yield for the process, the two-step, one pot tandem was then applied to the preparation of NPS R-568. Thus, 3-(2chlorophenyl)propanoic acid was treated with EDC, DMAP, and succinimide to generate propanoyl succinimide 29 in $82 \%$ yield (Scheme 5). The yield was $60 \%$ when the reaction was carried out on a multi-gram scale. The acyl succinimide was reacted with 1 equiv. of the chiral amine $(\boldsymbol{R})-\mathbf{3 0}$ to afford the amide which was not isolated. Lithium aluminum hydride was directly added to the reaction mixture which stirred for an additional $48 \mathrm{~h}$. This reaction afforded the target NPS R-568 in 56\% yield after chromatographic purification. When carried out on a multi-gram scale, the isolated chemical yield was $68 \%$.
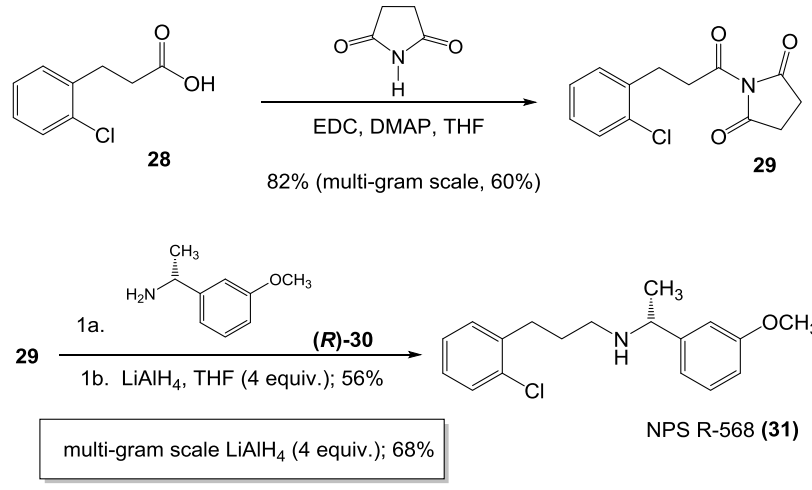

Scheme 5. Two-step, one pot synthesis of NPS R568.

In conclusion, a two-step, one pot reaction for the preparation of amines via acyl succinimides has been developed. The value in this methodology is in the reduction of the number of isolation steps necessary for the amine, which may be the more valuable component in the synthesis, to be employed in. The acyl succinimides can be easily prepared by a carbodiimide coupling reaction between carboxylic acids and succinimide. The coupling of acyl succinimides with amines generates amides with succinimide as the only byproduct. The in situ reduction of the amide generates the target amine and the succinimide byproduct is removed by aqueous extraction. This method has been employed in the synthesis of the calcimimetic agents cinacalcet, NPS R-467 and NPS R-568.

\section{Acknowledgements}

The authors acknowledge technical assistance from Delvis D. Dore, Jesse A. Wolfe, and Dipak Patel. The authors acknowledge support by the Department of Chemistry at Illinois State University. Accurate mass electrospray ionization (ESI) mass spectra were collected using high resolution MS instrumentation acquired through support by the National Science Foundation MRI Program under Grant No. CHE 1337497. 


\section{References}

1. (a) Goodman, C. A.; Eagles, J. B.; Rudahindwa, L.; Hamaker, C. G.; Hitchcock, S. R. Synth. Commun. 2013, 43, 2155-2164. (b) Boyd, H.; Leach, S. J.; Milligan, B. International J. Peptide and Protein Research 1972, 4, 117-122.

2. Abdel-Magid, A. F.; Mehrman, S. J. Org. Process Res. Dev., 2006, 10, 971-1031. (b) Baxter, E. W.; Reitz, A. B. Organic Reactions 2002, 59, 1-714. (c) Küenburg, B.; Czollner, L.; Frohlich, J.; Jordis, U. Org Proc. Res. Dev. 1999, 3, 425-431.

3. (a) Georg, G. I.; Harriman, G. C. B.; Hepperle, M.; Clowers, J. S.; vander Velde, D. G.; Himes, R. H. J. Org. Chem. 1996, 61, 2664-2676. (b) Greenstein, J. P.; Winitz, M. "Chemistry of the Amino Acids", Wiley: New York, 1961, vol. 2, pp. 887-901. (c) Schotten, C. Chem. Ber. 1884, 17, 2544-2547. (d) Baumann, E. Chem. Ber. 1886, 19, 3218-3222.

4. (a) del Pozo, C.; Keller, A. I.; Nagashima,T.; Curran, D. P. Org. Lett. 2007, 9, 4167-4170. (b) Ho, G.-J.; Emerson, K. M.; Mathre, D. J.; Shuman, R. F.; Grabowski, E. J. J. J. Org. Chem. 1995, 60, 3569-3570. (c) Williams, A.; Ibrahim, I. T. Chem. Rev. 1981, 81, 589-636.

5. (a) Menger, F. M.; Ladika, M. J. Am. Chem. Soc. 1987, 109, 3145-3146. (b) Bodansky, M.; Williams, N. J. J. Am. Chem. Soc. 1967, 89, 685689. (c) Bodansky, M.; Ondetti, M. A.; Levine, S. D.; Williams, N. J. J. Am. Chem. Soc. 1967, 89, 6753-6757. (d) Bodansky, M.; du Vigneaud, V. $J$. Am. Chem. Soc. 1959, 81, 5688-5691.

6. (a) Wilchek, M.; Knudsen, K. L.; Miron, T. Bioconjugate Chem. 1994, 5, 491-492. (b) Cline, G. W.; Hanna, S. B. J. Am. Chem. Soc. 1987, 109, 3087-3091. (c) Anderson, G. W.; Zimmerman, J. E.; Callahan, F. M. J. Am. Chem. Soc. 1964, 86, 1839-1842. (d) Anderson, G. W.; Zimmerman, J. E.; Callahan, F. M. J. Am. Chem. Soc. 1963, 85, 3039.

7. (a) Fujishima, S.-h.; Yasui, R.; Miki, T.; Ojida, A.; Hamachi, I. J. Am. Chem. Soc. 2012, 134, 39613964. (b) Hadd, A. G.; Birks, J. W. J. Org. Chem. 1996, 61, 2657-2663.

8. Yadav, J. S.; Thirupathi Reddy, P.; Nanda, S.; Rao, A. B. Tetrahedron: Asymm. 2002, 21, 3381-3385.

9. Shinde, G. B.; Niphade, N. C.; Deshmukh, S. P.; Toche, R. B.; Mathad, V. T. Org. Process Res. Dev. 2011, 15, 455-461.

10. Thiel, O. R.; Bernard, C.; Tormos, W.; Brewin, A.; Hirotani, S.; Murakami, K.; Saito, K.; Larsen, R. D.; Martinelli, M. J.; Reider, P. J. Tetrahedron Lett. 2008, 49, 13-15.

11. Ou, W.; Espinosa, S.; Melendez, H. J.; Farre, S. M.; Alvarez, J. L.; Torres, V.; Martínez, I.; Santiago, K.
M.; Ortiz-Marciales. J. Org. Chem. 2013, 78, 5314-5327.

12. Bijukumar, G.; Maloyesh, B.; Bhaskar, B. S.; Rajendra, A. Synth. Commun. 2008, 38, 1512-1517.

13. Geoghegan, K.; Kelleher, S.; Evans, P. J. Org. Chem. 2011, 76, 2187-2194.

14. Tewari, N.; Maheshwari, N.; Medhane, R.; Nizar, H.; Prasad, M. Org. Process Res. Dev. 2012, 16, 1566-1568.

15. Jiang, X.; Chu, L.; Qing, F.-L. J. Org. Chem. 2012, $77,1251-1257$.

16. Schreiber, K. C.; Fernandez, V. P. J. Org. Chem. 1960, 26, 1744-1747.

17. Ono, N.; Kawamura, H.; Maruyama, K. Bull. Chem. Soc. Jpn. 1989, 62, 3386-3388.

18. (a) Bonomini, M.; Giardinelli, A.; Morabito, C.; Di Silvestre, S.; Di Cesare, M.; Di Pietro, N.; Sirolli, V.; Formoso, G.; Amoroso, L.; Mariggio, M. A.; Pandolfi, A. PLoS ONE 2012, 7, e30682. (b) Pattaragarn, A.; Fox, J.; Alon, U. S.; Kidney international 2004, 65, 1684-1689. (c) Nemeth, E.. F.; Steffey, M. E.; Hammerland, L. G.; Hung, B. C. P.; Van Wagenen, B. C.; DelMar, E. G.; Baladrin, M. F. Proc. Natl. Acad. Sci. USA 1998, 95, 4040-4045.

19. Rao, R.; Shewalkar, M. P.; Nandipati, R.; Yadav, J. S.; Khagga, M.; Shinde, D. B. Synth. Commun. 2012, 42, 589-598.

20. Fernandez, I.; Valdivia, V.; Khiar, N. J. Org. Chem. 2008, 73, 745-748.

21. Han, K.; Kim, Y. Park, J.; Kim, J.-J. Tetrahedron Lett. 2010, 51, 3536-3537.

22. Banerjee, S.; Smith, B.; Hitchcock, S. R. Appl. Organomet. Chem. 2010, 25, 105-109.

23. (a) Atobe, M.; Yamazaki, N.; Kibayashi, C. J. Org. Chem. 2004, 69, 5595-5607. (b) Yamazaki, N.; Atobe, M.; Kibayashi, C. Tetrahedron Lett. 2001, 42, 5029-5032.

24. Arava Reddy, V.; Gorentla, L.; Dubney, P. K. Der Pharma Chemica 2011, 3, 426-433.

25. Gautier, F.-M.; Jones, S.' Li, X.; Martin, S. J. Org. Biomol. Chem. 2011, 9, 7860-7868.

26. Chen, C.-C.; Ho, J.-C.; Chang, N.-C. Tetrahedron 2008, 64, 10350-10354.

27. Hansen, M. C.; Buchwald, S. L. Tetrahedron Lett. 1999, 40, 2033-2034.

28. Barmore, R. M.; Logan, S. R.; VanWagenen, B. C. Tetrahedron Lett. 1998, 39, 3451-3454. 